Research Paper

\title{
Involvement of endothelial nitric oxide synthase gene variants in the aggressiveness of uterine cervical cancer
}

\author{
Wei-Chen Hung1,\#, Ting-Feng Wu ${ }^{2,3, \#, ~ S o o-C h e e n ~} \mathrm{Ng}^{2,3}$, Yueh-Chun Lee1,3,4, Huang-Pin Shen ${ }^{1,2,3}$, Shun-Fa \\ Yang 1,5 , Po-Hui Wang 1,2,3, \\ 1. Institute of Medicine, Chung Shan Medical University, Taichung, Taiwan \\ 2. Department of Obstetrics and Gynecology, Chung Shan Medical University Hospital, Taichung, Taiwan \\ 3. School of Medicine, Chung Shan Medical University, Taichung, Taiwan \\ 4. Radiation Oncology Department, Chung Shan Medical University Hospital, Taichung, Taiwan \\ 5. Department of Medical Research, Chung Shan Medical University Hospital, Taichung, Taiwan \\ \#These authors contributed equally to this work. \\ $\square$ Corresponding author: Po-Hui Wang, MD, PhD, Institute of Medicine, Chung Shan Medical University, 110, Section 1, Chien-Kuo North Road, Taichung, \\ 40201, Taiwan Tel.: 886-4-24739595 ext. 21721; Fax: 884-4-24738493. E-mail: ginhow84921344@yahoo.com.tw \\ (c) Ivyspring International Publisher. This is an open access article distributed under the terms of the Creative Commons Attribution (CC BY-NC) license \\ (https://creativecommons.org/licenses/by-nc/4.0/). See http://ivyspring.com/terms for full terms and conditions.
}

Received: 2019.01.16; Accepted: 2019.05.10; Published: 2019.06.02

\begin{abstract}
To date, few studies explore the involvement of endothelial nitric oxide synthase (eNOS) gene variants in uterine cervical cancer. Therefore, we conducted this study to assess the clinical implication of eNOS in cervical carcinogenesis, clinicopathological characteristics and patient survival. One hundred and seventeen patients with cervical invasive cancer and 95 with preinvasive lesions and 330 control women were consecutively enrolled. Real time polymerase chain reaction was used to examine the genotypic distributions of eNOS single nucleotide polymorphisms (SNPs) rs $1799983(894 \mathrm{G}>\mathrm{T})$ ) at the exon 7 region and rs2070744 $(-786 \mathrm{~T}>\mathrm{C})$ at the promoter region. Our results indicated no significant associations among genotypic distributions of eNOS SNPs and patients with cervical invasive cancer and those with preinvasive lesions as well as normal controls. However, cervical cancer patients with genotypes TC/CC in eNOS SNP rs2070744 carried less risk of advanced stage [odds ratios $(\mathrm{OR})=0.30,95 \%$ confidence interval $(\mathrm{Cl})=0.09-0.97, p=0.036$ ], parametrium invasion $(\mathrm{OR}=0.16,95 \% \mathrm{Cl}=0.02-0.75, p=0.009)$ and pelvic lymph node metastasis $(\mathrm{OR}=0.12,95 \% \mathrm{Cl}=0.01-0.89, p=0.016)$. In conclusion, although eNOS SNPs rs2070744 and rs 1799983 do not display significant associations with cervical carcinogenesis and patient survival, cervical cancer patients with genotypes TC/CC in rs2070744 carry less risk of advanced stage, parametrium invasion and pelvic lymph node metastasis in Taiwan.
\end{abstract}

Key words: endothelial nitric oxide synthase gene, single nucleotide polymorphism, uterine cervical cancer, parametrium invasion, pelvic lymph node metastasis

\section{Introduction}

Nitric oxide (NO) is a free radical that acts as a paracrine and autocrine signaling molecule in human body; for example, it is released by the endothelia cells of the blood vessels and causes vasodilatation. However, studies have showed that NO may also play an important role in cancer related pathophysiology such as modifying the expression of oncogene and tumor suppressor gene, tumor angiogenesis and metastasis [1]. NO has different actions in various human cancers such as head and neck cancer, breast cancer, gastric cancer, lung cancer and gynecologic cancers [1-4].

In women with cervical intraepithelial neoplasia, NO metabolite level in cervicovaginal secretion was significantly higher compared to bacterial vaginosis and normal control [5]. Immunohistochemistry study on high-risk human papillomavirus (HPV) infected cervical intraepithelial neoplasia cells showed that 
these cells have more intense mutagenic nitrative DNA lesion [6]. Another study was conducted to evaluate the effect of $\mathrm{NO}$ on carcinogenesis in Human Papillomavirus-infected cells [7]. They concluded that $\mathrm{NO}$ was associated with decreased $\mathrm{pRb}$ and $\mathrm{p} 53$ levels, decreased apoptotic activity, and increased survival of mutant cells.

NO was formed from the transformation of L-arginine to L-citrulline by nitric oxide synthase (NOS) [8-12]. Endothelial nitric oxide synthase (eNOS) is one of the four isoforms of NOS. eNOS is encoded by the NOS3 gene, located in 7q35-q36[13]. Few polymorphisms were reported on NOS3 gene including rs1799983, intron 4a/b, and rs2070744 [11]. Recently, studies have been conducted to evaluate the association between eNOS polymorphisms and various human cancers [13-17]. eNOS genetic polymorphisms were associated with increased risk of gastric cancer [13] and were also significantly associated with epidermal growth factor receptor (EGFR) mutation types of lung adenocarcinoma which might indicate increased invasiveness of the cancer [14].

At present there is no study evaluating the association between eNOS polymorphisms and the carcinogenesis or clinicopathological variables in uterine cervical cancer. The aim of our study was to evaluate the association between eNOS genetic polymorphisms and the risk of cervical cancer which compared between normal control group, high grade cervical intraepithelial neoplasia (CIN) group and invasive cervical cancer group. We also evaluated the association between eNOS genetic variants with cancer stage, histological type, tumor invasiveness and metastasis as well as tumor recurrence and overall survival.

\section{Materials and Methods}

\section{Data source and studied subjects}

The study was conducted by enrolling individuals retrospectively. One hundred and seventeen patients with invasive cancer and 95 patients with high-grade cervical intraepithelial neoplasia (CIN) of uterine cervix as well as 330 normal controls were consecutively recruited at the Department of Obstetrics and Gynecology in Chung Shan Medical University in Taichung, Taiwan from February 1994 to October 2014. Patients with high-grade CIN were known as precancerous lesions and received abdominal hysterectomy or simple trachelectomy. All studied subjects were Taiwanese women who resided in central Taiwan. The institutional review board of Chung Shan Medical
University Hospital approved this study (CSMUH No: CS11152).

\section{Selection of single nucleotide polymorphisms (SNPs) of endothelial nitric oxide synthase (eNOS) gene and DNA extraction from all subjects}

In this study, two eNOS SNPs were selected according to International HapMap Project data and previous studies [18, 19]. Genetic polymorphisms rs1799983 $(894 \mathrm{G}>\mathrm{T})$ at the exon 7 region and rs2070744 $(-786 \mathrm{~T}>\mathrm{C})$ at the promoter region were included which SNPs were associated with tumor progression in various cancers [14, 17, 20]. Blood specimens were collected by the laboratory staffs from all participants using a standard venipuncture technique and deposed into Vacutainer tubes containing ethylenediaminetetraacetic acid. The materials were stored at $4^{\circ} \mathrm{C}$ immediately. Deoxyribonucleic acid was extracted from peripheral vein blood leukocytes according to manufacturer's protocol as described in detail previously [21]. Assessment of allelic discrimination for the two eNOS SNPs were performed by using the TaqMan assay with an ABI StepOnePlus ${ }^{\mathrm{TM}}$ Real-Time PCR System.

\section{Statistical analysis}

Analysis of variance was used to compare the age difference among patients with invasive cancer and those with preinvasive lesions of uterine cervix as well as control women and then Scheffe test was used for post hoc analysis. Chi-square or Fisher's exact tests were used to relate genotypic distributions of eNOS SNPs to the incidence of cervical neoplasias (including preinvasive lesions and invasive cancer). The adjusted odds ratios (AORs) with their 95\% confidence intervals (CIs) were applied to determine the associations among genotypic distributions of eNOS SNPs and the incidence of cervical neoplasias using the logistic and multinomial logistic regression models after controlling for age. Univariate Kaplan-Meier model and multivariate Cox proportional hazard model with backward stepwise method were applied to associate eNOS SNPs with recurrence probability and overall survival of patients with cervical invasive cancer, with adjusting for various clinicopathological parameters, relative to recurrence and survival time or until closing date of the study (March 31, 2018). The SPSS, version 18.0 and WinPepi Software, version 10.0 were used for statistical analysis. $p<0.05$ was regarded as a statistically significant difference. 


\section{Results}

\section{Age and genotypic distributions}

The age distribution was significantly different between patients with cervical neoplasia and normal control women $(50.0 \pm 13.6$ vs. $43.7 \pm 10.4, p<0.001)$. Based on ANOVA with Scheffe test for post hoc analysis, there was significant difference for age distribution between patients with cervical invasive cancer and those with preinvasive lesion $(55.0 \pm 12.5$ vs. $44.0 \pm 12.4, p<0.001)$, and between those with cervical cancer and control women $(55.0 \pm 12.5$ vs. 43.7 $\pm 10.4, p<0.001$ ) but not significant between those with preinvasive lesions and control women $(44.0 \pm 12.4$ vs. $43.7 \pm 10.4, p=0.977$ ).

\section{Relationship of eNOS genetic variant distributions with uterine cervical carcinogenesis}

The genotypic distributions of eNOS SNPs in the Taiwanese women with cervical neoplasias and normal control women are shown in Table 1. There were no significantly different distributions of eNOS SNPs rs1799983 and rs2070744 between patients with cervical neoplasias and normal control women. No significant differences were found for the two SNPs between patients with cervical neoplasias and normal controls even after controlling for age. Although the cervical neoplasias group was subdivided into invasive cancer and preinvasive lesions subgroups, we could not find significant associations among genotypic distributions of these eNOS SNPs and patients with cervical invasive cancer and those with preinvasive lesions as well as normal controls (Table
2). After controlling for age, no significant associations were still presented.

Table 1. Genetic polymorphism distributions of the endothelial nitric oxide synthase gene in Taiwanese women with neoplasias of the uterine cervix and normal controls.

\begin{tabular}{|c|c|c|c|c|c|c|}
\hline Variables & $\begin{array}{l}\text { Normal } \\
\text { controls } \\
(\mathrm{n}=330, \%)\end{array}$ & $\begin{array}{l}\text { Cervical } \\
\text { neoplasias } \\
(\mathrm{n}=212, \%)\end{array}$ & $\begin{array}{l}\text { ORs }(95 \% \\
\text { CIs) }\end{array}$ & $\begin{array}{l}p \\
\text { values }\end{array}$ & $\begin{array}{l}\text { AORs } \\
(95 \% \text { CIs })^{b}\end{array}$ & $\begin{array}{l}\text { Adjusted } \\
p \text { values }\end{array}$ \\
\hline \multicolumn{7}{|l|}{ rs1799983 } \\
\hline $\mathrm{GG}^{\mathrm{c}}$ & $268(81.2)$ & $171(80.7)$ & 1.00 & 0.396 & 1.00 & 0.451 \\
\hline GT & 60 (18.2) & 37 (17.5) & $\begin{array}{l}0.97 \\
(0.62-1.52)\end{array}$ & 0.883 & $\begin{array}{l}0.95 \\
(0.60-1.51)\end{array}$ & 0.827 \\
\hline TT & $2(0.6)$ & $4(1.9)$ & $\begin{array}{l}3.14 \\
(0.57-17.30)\end{array}$ & 0.190 & $\begin{array}{l}2.99 \\
(052-17.17)\end{array}$ & 0.219 \\
\hline$G^{c}{ }^{c}$ & $268(81.2)$ & $171(80.7)$ & 1.00 & 0.873 & 1.00 & 0.941 \\
\hline GT/TT & $62(18.8)$ & 41 (19.3) & $\begin{array}{l}1.04 \\
(0.67-1.61)\end{array}$ & & $\begin{array}{l}1.02 \\
(0.65-1.60)\end{array}$ & \\
\hline GG/GTc & $328(98.7)$ & $208(98.1)$ & 1.00 & 0.216 & 1.00 & 0.185 \\
\hline $\mathrm{TT}$ & $2(0.6)$ & 4 (1.9) & $\begin{array}{l}3.15 \\
(0.57-17.4)\end{array}$ & & $\begin{array}{l}3.17 \\
(0.58-17.46)\end{array}$ & \\
\hline \multicolumn{7}{|l|}{ rs2070744 } \\
\hline $\mathrm{TT}^{\mathrm{c}}$ & $259(78.5)$ & $178(82.0)$ & 1.00 & 0.273 & 1.00 & 0.383 \\
\hline $\mathrm{TC}$ & $68(20.6)$ & 33 (15.6) & $\begin{array}{l}0.71 \\
(0.45-1.12)\end{array}$ & 0.136 & $\begin{array}{l}0.73 \\
(0.45-1.16)\end{array}$ & 0.183 \\
\hline $\mathrm{CC}$ & $3(0.9)$ & $1(0.5)$ & $\begin{array}{l}0.49 \\
(0.05-4.70)\end{array}$ & 0.532 & $\begin{array}{l}0.60 \\
(0.06-5.97)\end{array}$ & 0.663 \\
\hline $\mathrm{TT}^{\mathrm{c}}$ & $259(78.5)$ & $178(84.0)$ & 1.00 & 0.115 & 1.00 & 0.168 \\
\hline $\mathrm{TC} / \mathrm{CC}$ & $71(21.5)$ & $34(16.0)$ & $\begin{array}{l}0.70 \\
(0.44-1.09)\end{array}$ & & $\begin{array}{l}0.72 \\
(0.45-1.15)\end{array}$ & \\
\hline $\mathrm{TT} / \mathrm{TC}^{\mathrm{c}}$ & 327 (99.1) & $211(99.5)$ & 1.00 & 1.000 & 1.00 & 0.571 \\
\hline $\mathrm{CC}$ & $3(0.9)$ & $1(0.5)$ & $\begin{array}{l}0.52 \\
(0.05-5.00)\end{array}$ & & $\begin{array}{l}0.52 \\
(0.05-5.02)\end{array}$ & \\
\hline
\end{tabular}

Statistical analysis: logistic regression model or chi-square or Fisher's exact tests. aCervical neoplasias included preinvasive lesions and invasive cancer of the uterine cervix.

bThe adjusted $p$ values as well as adjusted odds ratios and their $95 \%$ confident intervals were calculated by logistic regression model after controlling age.

cUsed as a reference for comparison to calculate the odds ratios of other genotypes. $95 \%$ CIs, $95 \%$ confidence intervals; AORs, adjusted odds ratios.

Table 2. Genotypic distributions of the endothelial nitric oxide synthase gene polymorphisms in Taiwanese women with uterine cervical invasive cancer or preinvasive lesions and normal controls.

\begin{tabular}{|c|c|c|c|c|c|c|c|c|}
\hline Variables & $\begin{array}{l}\text { Normal controls }(\mathrm{n}=330 \text {, } \\
\%)\end{array}$ & $\begin{array}{l}\text { Pre-invasive lesions }(\mathrm{n}=95, \\
\%)\end{array}$ & $\begin{array}{l}\text { Invasive cancer }(\mathrm{n}=117 \text {, } \\
\%)\end{array}$ & $\begin{array}{l}p \\
\text { values }\end{array}$ & $\begin{array}{l}\text { AORs }(95 \% \\
\text { CIs) }\end{array}$ & $\begin{array}{l}\text { Ad } p \\
\text { values }\end{array}$ & $\begin{array}{l}\text { AORs } \\
(95 \% \text { CIs })^{b}\end{array}$ & $\begin{array}{l}\text { Ad } p \\
\text { values }\end{array}$ \\
\hline \multicolumn{9}{|l|}{ rs1799983 } \\
\hline $\mathrm{GG}^{\mathrm{c}}$ & $268(81.2)$ & 78 (82.1) & $93(79.5)$ & 0.517 & 1.00 & & 1.00 & \\
\hline GT & $60(18.2)$ & $16(16.8)$ & 21 (17.9) & & $0.91(0.50-1.68)$ & 0.773 & $1.00(0.55-1.81)$ & 0.994 \\
\hline TT & $2(0.6)$ & $1(1.1)$ & $3(2.6)$ & & $1.71(0.15-19.15)$ & 0.662 & $4.57(0.67-31.41)$ & 0.122 \\
\hline $\mathrm{GG}^{\mathrm{c}}$ & $268(81.2)$ & $78(82.1)$ & $93(79.5)$ & 0.879 & 1.00 & & 1.00 & \\
\hline GT/TT & $62(18.8)$ & 17 (17.9) & $24(20.5)$ & & $0.94(0.52-1.70)$ & 0.839 & $1.12(0.63-1.97)$ & 0.702 \\
\hline GG/GTc & $328(99.4)$ & 94 (98.9) & $114(97.4)$ & 0.142 & 1.00 & & 1.00 & \\
\hline $\mathrm{TT}$ & $2(0.6)$ & $1(1.1)$ & $3(2.6)$ & & $1.74(0.16-19.41)$ & 0.652 & $4.57(0.67-31.29)$ & 0.122 \\
\hline \multicolumn{9}{|l|}{ rs2070744 } \\
\hline $\mathrm{TT}_{\mathrm{c}}$ & $259(78.5)$ & $81(85.3)$ & $97(82.9)$ & 0.426 & 1.00 & & 1.00 & \\
\hline $\mathrm{TC}$ & $68(20.6)$ & 13 (13.7) & $20(17.1)$ & & $0.61(0.32-1.17)$ & 0.135 & $0.85(0.47-1.54)$ & 0.580 \\
\hline $\mathrm{CC}$ & $3(0.9)$ & $1(1.1)$ & $0(0.0)$ & & $1.07(0.11-10.44)$ & 0.953 & u.a. & u.a. \\
\hline $\mathrm{TT}^{\mathrm{c}}$ & $259(78.5)$ & $81(85.3)$ & $97(82.9)$ & 0.264 & 1.00 & & 1.00 & \\
\hline $\mathrm{TC} / \mathrm{CC}$ & $71(21.5)$ & $14(14.7)$ & $20(17.1)$ & & $0.63(0.34-1.18)$ & 0.149 & $0.82(0.45-1.48)$ & 0.504 \\
\hline $\mathrm{TT} / \mathrm{TC}^{\mathrm{c}}$ & 327 (99.1) & 94 (98.9) & $117(100.0)$ & 0.635 & 1.00 & & 1.00 & \\
\hline $\mathrm{CC}$ & $3(0.9)$ & $1(1.1)$ & $0(0.0)$ & & $1.17(0.12-11.34)$ & 0.895 & u.a. & u.a. \\
\hline
\end{tabular}

Statistical analysis: multinomial logistic regression or chi-square or Fisher's exact tests.

aAdjusted $p$ values and adjusted odds ratios with their 95\% CIs were estimated using multinomial logistic regression models after controlling age between patients with cervical preinvasive lesions and control women.

bAdjusted $p$ values and adjusted odds ratios with their 95\% CIs were determined using multinomial logistic regression models after controlling age between patients with cervical invasive cancer and control women.

cUsed as a reference for comparison to calculate the odds ratios of other genotypes.

AORs, adjusted odds ratios; $95 \%$ CIs, 95\% confidence intervals; Ad, adjusted; u.a., unavailable. 
Table 3. Association of genotypic distributions of endothelial nitric oxide synthase genetic variants rs2070744 with clinicopathological variables of the patients with invasive cancer of uterine cervix.

\begin{tabular}{|c|c|c|c|c|}
\hline & rs20 & & & \\
\hline Variables $^{a}$ & $\mathbf{T T}^{\mathbf{b}}$ & TC/CC & $p$ value & ORs (95\% CIs) \\
\hline Clinical stage & & & $0.036^{c}$ & \\
\hline stage $\mathrm{I}^{\mathrm{b}}$ & 53 & 16 & & 1.00 \\
\hline$\geq$ stage II & 44 & 4 & & $0.30(0.09-0.97)$ \\
\hline Pathologic type & & & 1.000 & \\
\hline $\begin{array}{l}\text { squamous cell } \\
\text { carcinomab }^{\mathrm{b}}\end{array}$ & 82 & 17 & & 1.00 \\
\hline adenocarcinoma & 15 & 3 & & $0.97(0.25-3.70)$ \\
\hline Stromal invasion depth & & & 0.493 & \\
\hline$\leq 10 \mathrm{~mm}^{\mathrm{b}}$ & 49 & 12 & & 1.00 \\
\hline$>10 \mathrm{~mm}$ & 46 & 8 & & $0.71(0.23-2.10)$ \\
\hline Tumor diameter ${ }^{\mathrm{b}}$ & & & 0.131 & \\
\hline$\leq 4 \mathrm{~cm}$ & 50 & 14 & & 1.00 \\
\hline$>4 \mathrm{~cm}$ & 47 & 6 & & $0.46(0.13-1.40)$ \\
\hline Parametrium & & & $0.009 c$ & \\
\hline no invasion ${ }^{b}$ & 57 & 18 & & 1.00 \\
\hline invasion & 39 & 2 & & $0.16(0.02-0.75)$ \\
\hline Vagina & & & 0.546 & \\
\hline no invasion ${ }^{b}$ & 61 & 14 & & 1.00 \\
\hline invasion & 36 & 6 & & $0.73(0.21-2.24)$ \\
\hline Pelvic lymph node & & & $0.016^{c}$ & \\
\hline no metastasis ${ }^{b}$ & 66 & 19 & & 1.00 \\
\hline metastasis & 30 & 1 & & $0.12(0.01-0.89)$ \\
\hline
\end{tabular}

Statistical analyses: chi-square or Fisher's exact tests, $c p<0.05$

aSome clinicopathological data could not be obtained from the patients with

cervical invasive cancer due to incomplete records of medical chart

bAs a reference. ORs, odds ratios; $95 \%$ CIs, $95 \%$ confidence intervals.

\section{The relationships of eNOS genetic variants with clinicopathological parameters in the cervical cancer patients}

There was no genotype CC of eNOS rs2070744 presented in cervical invasive cancer patients. Then, genotype CC was grouped with TC as genotypes TC/CC in associating eNOS re2070744 with clinicopathological variables. We found that cervical cancer patients with genotypes TC/CC in eNOS SNP rs2070744 carried less risk of advanced stage $(\mathrm{OR}=0.30,95 \% \mathrm{CI}=0.09-0.97, p=0.036)$, parametrium invasion $(\mathrm{OR}=0.16,95 \% \mathrm{CI}=0.02-0.75, p=0.009)$ and pelvic lymph node metastasis (OR $=0.12,95 \%$ $\mathrm{CI}=0.01-0.89, p=0.016)$ than those with genotype TT (Table 3). No significant associations were found between eNOS SNP rs1799983 and clinicopathological variants (data not showed).

\section{Univariate analysis for the recurrence probability and overall survival in cervical cancer patients based on eNOS SNP rs2070744 and clinicopathological variables}

We further evaluated the association of eNOS SNP rs2070744 with the recurrence probability and overall survival of cervical cancer patients. In univariate analysis, we found that cervical cancer patients with genotype TC/CC of eNOS SNP rs2070744 have no significant association in recurrence probability compared with genotype TT [hazard ratio $(\mathrm{HR})=0.98,95 \% \mathrm{CI}=0.34-2.87, p=0.972$; TT as a reference] (Table 4). We found the following to be significantly associated with recurrence probability: stage, stromal invasion depth, tumor diameter, vagina invasion and pelvic lymph node metastasis (Table 4). However, patients with genotype TC/CC tended to have better overall survival $(\mathrm{HR}=0.18,95 \% \mathrm{CI}=0.02-1.29, p=0.053)$, using TT as a reference. The characteristics those were associated with overall survival were showed in the following: stage, stromal invasion depth, tumor diameter, parametrium invasion and lymph node metastasis (Table 4).

Table 4. Univariate analysis for the associations of endothelial nitric oxide synthase genetic polymorphism and various clinicopatholgical parameters with the recurrence probability and overall survival of the patients with uterine cervical cancer.

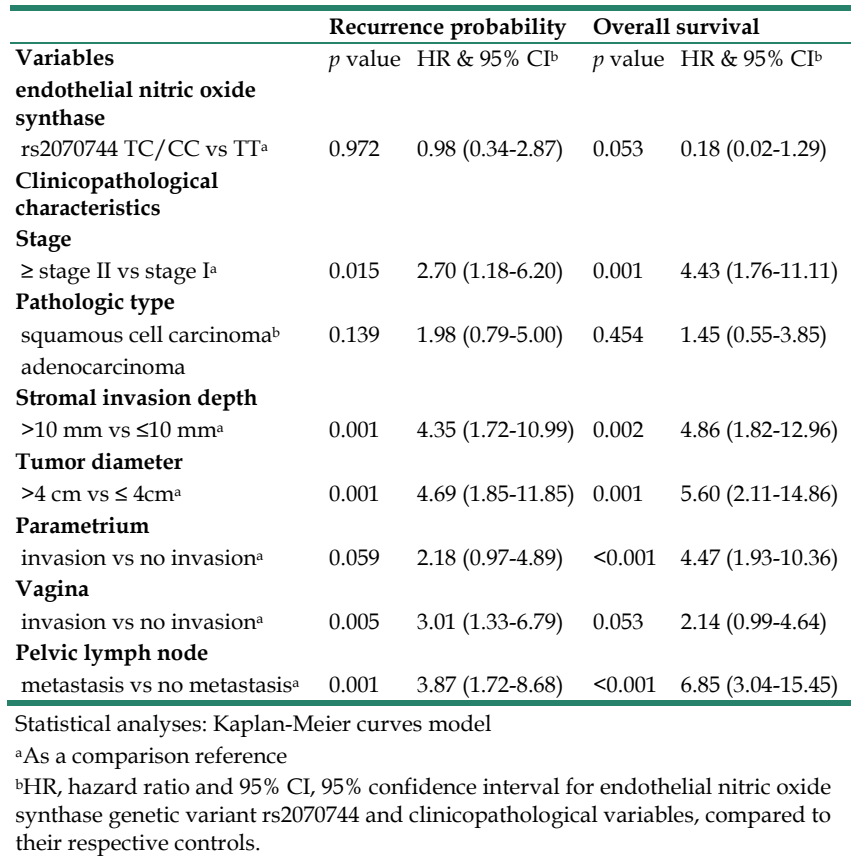

\section{Multivariate analysis for the recurrence probability and overall survival in cervical cancer patients based on eNOS SNP rs2070744 and clinicopathological variables}

In multivariate analysis, we found no association of eNOS SNP rs2070744 with recurrence probability and overall survival $(\mathrm{HR}=1.18,95 \% \mathrm{CI}=0.37-3.78$, $p=0.781$; for recurrence probability; $\mathrm{HR}=0.30,95 \%$ $\mathrm{CI}=0.04-2.32, p=0.250$ for overall survival; Table 5). Larger tumor diameter could be the only independent predictor of worse recurrence probability for cervical cancer patients $(\mathrm{HR}=3.69,95 \% \mathrm{CI}=1.34-10.11, p=0.011$; Table 5). Deeper stromal invasion depth $(\mathrm{HR}=3.11$, 95\% CI=1.12-8.65, $p=0.030)$ and pelvic lymph node metastasis $\quad(\mathrm{HR}=4.90,95 \% \quad \mathrm{CI}=2.06-11.64, \quad p<0.001$; 
Table 5) could independently predict the poorer overall survival. Endothelial nitric oxide synthase SNP rs1799983 also exhibited no association with the recurrence probability and overall survival of cervical cancer patients in multivariate analysis (data not showed).

Table 5. Multivariate analysis for the associations of endothelial nitric oxide synthase genetic polymorphism and various clinicopatholgical parameters with the recurrence probability and overall survival of the patients with uterine cervical cancer.

\begin{tabular}{|c|c|c|c|c|}
\hline \multirow[b]{2}{*}{ Variables } & \multicolumn{2}{|c|}{ Recurrence probability } & \multicolumn{2}{|c|}{ Overall survival } \\
\hline & $p$ value & HR \& $95 \% \mathrm{CI}^{\mathrm{b}}$ & $p$ value & HR \& 95\% CIb \\
\hline \multicolumn{5}{|l|}{$\begin{array}{l}\text { endothelial nitric oxide } \\
\text { synthase }\end{array}$} \\
\hline rs2070744 TC/CC vs TTa & 0.781 & $1.18(0.37-3.78)$ & 0.250 & $0.30(0.04-2.32)$ \\
\hline \multicolumn{5}{|l|}{$\begin{array}{l}\text { Clinicopathological } \\
\text { characteristics }\end{array}$} \\
\hline \multicolumn{5}{|l|}{ Stromal invasion depth } \\
\hline$>10 \mathrm{~mm}$ vs $\leq 10 \mathrm{~mm}^{\mathrm{a}}$ & 0.322 & $1.84(0.55-6.16)$ & 0.030 & $3.11(1.12-8.65)$ \\
\hline \multicolumn{5}{|l|}{ Tumor diameter } \\
\hline$>4 \mathrm{~cm}$ vs $\leq 4 \mathrm{~cm}^{\mathrm{a}}$ & 0.011 & $3.69(1.34-10.11)$ & 0.304 & $2.04(0.52-7.94)$ \\
\hline \multicolumn{5}{|l|}{ Pelvic lymph node } \\
\hline metastasis vs no metastasis & 0.063 & $2.30(0.96-5.52)$ & $<0.001$ & $4.90(2.06-11.64)$ \\
\hline aAs a comparison reference & & & & \\
\hline
\end{tabular}

\section{Discussion}

Uterine cervical cancer was the third common type of gynecological cancer in Taiwan according to the 2015 cancer registry annual report. The process of carcinogenesis from cervical epithelial cells to cervical intraepithelial neoplasia and finally transformed into invasive cervical cancer after persistent HPV infection was complicated $[22,23]$. The local immune response was also reported to play a critical determinant in cervical carcinogenesis after persistent infection with oncogenic HPV infections; and genetic variation in the involved genes were further showed to have an impact on the risk of developing cervical cancer, as well as progression and survival among cervical cancer patients [24]. However, the associations were subtle and results diverse among different populations. Other additional host-cell changes and genetic loci might contribute to the carcinogenesis and progression of this disease. The eNOS polymorphism rs2070744 was identified as a factor associated with the risk of gastric cancer, but no association was identified between eNOS rs1799983 and ovarian cancer [11, 25]. In contrast, the eNOS genetic polymorphism rs1799983 has been reported to be concerned with the breast cancer risk in Taiwanese women [15].

In our present study, we evaluated the association between eNOS polymorphisms including SNP -786 $\mathrm{T}>\mathrm{C} \quad(\mathrm{rs} 2070744)$ and $\mathrm{SNP}$ 894G $>\mathrm{T}$ (rs1799983) and the cervical carcinogenesis. To our knowledge, this was one of the few studies that evaluated the effect of eNOS polymorphisms on gynecology cancer. Our study showed different results. There was no significant difference between normal control group and the cervical neoplasias group (including cervical high grade CIN and invasive cancer) in various genotype combinations for the two eNOS polymorphisms. The result was same when we stratified the cervical neoplasias group into CIN group and invasive cancer group and compared with normal controls group. Few meta-analysis studies have been conducted to evaluate the overall cancer risk of eNOS polymorphisms, however the results were still conflicting among the meta-analysis reports [26-28]. Haque et al. and Zhang et al. reported no significant association of SNP 894G >T (rs1799983) with cancer susceptibility [27, 28]. However, Wu et al. reported genotype TT in eNOS $894 \mathrm{G}>\mathrm{T}$ was associated with increased susceptibility for female malignancy and breast cancer [26]. SNP -786 T >C was not related to breast cancer risk. Zhang et al. found that there is significant association between $-786 \mathrm{~T}>\mathrm{C}$ polymorphism and breast cancer risk [28]. None of these reports mention about the association between eNOS polymorphisms and the risk of uterine cervical cancer.

Besides from carcinogenesis, eNOS polymorphisms might associated with various clinicopathological variables of invasive cervical cancer. In this study we compared patients having genotypes TC/CC with genotype TT in eNOS genetic polymorphism rs2070744. We found that cervical cancer patients with genotypes TC/CC carried less risk of advanced stage, parametrium invasion and pelvic lymph node metastasis. No associations were found between eNOS genetic polymorphism rs1799983 with various clinicopathological variables. In a study that evaluated the effect of eNOS genetic polymorphism on the metastatic status and vascular invasion of patients with breast cancer, $\mathrm{T}$ allele frequency at the NOS3 SNP rs2070744 was significantly associated with vascular invasion [29]. T allele reduction associated with decrease of vascular invasion in these patients and may have a favorable prognosis. Our study has comparable results that patients with genotypes TC/CC (T allele reduction) in NOS3 polymorphism rs2070744 have less metastasis and parametrium invasion which might indicate better prognosis. Another study was conducted in a group of Korean women with breast cancer [30]. Lee et al. found that $-786 \mathrm{C}$ allele in eNOS SNP rs2070744 was marginally associated with decreased risk for invasive breast cancer with lymph node involvement.

In our present study, we also evaluated the effect of eNOS genetic polymorphisms on recurrence 
probability and overall survival of cervical cancer patients. In eNOS rs2070744 (SNP -786 T >C), patients with genotype TC/CC tended to have better overall survival compared to genotype TT in univariate analysis. However, after controlling for other clinical factors in multivariate analysis, we found that eNOS genetic polymorphisms rs2070744 and rs1799983 have no significant effect on recurrence probability and overall survival in cervical cancer patients. In patients with hepatocellular carcinoma, eNOS polymorphisms have significant influence on the response to anti-angiogenic drugs [31]. eNOS -786 TT and eNOS 894 GG genotypes were significantly associated with a lower median progression-free survival than other genotypes in these patients. Another study has evaluated the influence of eNOS polymorphisms expression on survival in metastatic breast cancer patients [32]. These patients were treated with bevacizumab plus chemotherapy. Patients with eNOS 894 TT genotype showed significant lower progression-free survival compared with GG genotype but no differences in overall survival.

There were two limitations in the present study. Firstly, the sample size was small especially for the invasive cervical cancer group which might underestimate the actual association between eNOS polymorphisms and the carcinogenesis of cervical cancer. Secondly, data on HPV infection in our study subjects lacked. HPV tests were not popular in Taiwan because of the conservative attitude of Taiwanese women. Although HPV infection rates in high-grade squamous intraepithelial lesions and invasive cancer of uterine cervix have been reported to be $84.3 \%-100 \%$ based on the study by the Taiwan Cooperative Oncologic Group [33], Taiwanese women were unwilling to pay for HPV tests if their papanicolaou smear revealed normal because HPV tests were not covered under the National Health Insurance program. To our knowledge, this is the first study that evaluated the association of endothelial NO synthase gene polymorphisms with cervical cancer carcinogenesis, various clinicopathologic factors and patient survival. In conclusion, although eNOS SNPs rs2070744 and rs1799983 are not showed to display significant associations with cervical carcinogenesis and patient survival, cervical cancer patients with genotypes TC/CC in rs2070744 carry less risk of advanced stage, parametrium invasion and pelvic lymph node metastasis in Taiwan.

\section{Acknowledgments}

This study was supported by research grants from Ministry of Science and Technology (MOST 107-2314-B-040-017-MY3) and Chung Shan Medical
University Hospital (CSH-2018-D-004; CSH-2019D-003).

\section{Competing Interests}

The authors have declared that no competing interest exists.

\section{References}

[1] Choudhari SK, Chaudhary M, Bagde S, Gadbail AR, Joshi V. Nitric oxide and cancer: a review. World J Surg Oncol 2013; 11: 118

[2] Rieder J, Jahnke R, Schloesser M, Seibel M, Czechowski M, Marth C, et al. Nitric oxide-dependent apoptosis in ovarian carcinoma cell lines. Gynecol Oncol 2001; 82: 172-176.

[3] Shafran Y, Zurgil N, Ravid-Hermesh O, Sobolev M, Afrimzon E, Hakuk Y, et al. Nitric oxide is cytoprotective to breast cancer spheroids vulnerable to estrogen-induced apoptosis. Oncotarget 2017; 8: 108890-108911.

[4] Butcher LD, den Hartog G, Ernst PB, Crowe SE. Oxidative Stress Resulting From Helicobacter pylori Infection Contributes to Gastric Carcinogenesis. Cell Mol Gastroenterol Hepatol 2017; 3: 316-322.

[5] Tavares-Murta BM, de Resende AD, Cunha FQ, Murta EF. Local profile of cytokines and nitric oxide in patients with bacterial vaginosis and cervical intraepithelial neoplasia. Eur J Obstet Gynecol Reprod Biol 2008; 138: 93-99.

[6] Hiraku Y, Tabata T, Ma N, Murata M, Ding X, Kawanishi S. Nitrative and oxidative DNA damage in cervical intraepithelial neoplasia associated with human papilloma virus infection. Cancer Sci 2007; 98: 964-972.

[7] Wei L, Gravitt PE, Song H, Maldonado AM, Ozbun MA. Nitric oxide induces early viral transcription coincident with increased DNA damage and mutation rates in human papillomavirus-infected cells. Cancer Res 2009; 69: 4878-4884.

[8] Wang L, Shi GG, Yao JC, Gong W, Wei D, Wu TT, et al. Expression of endothelial nitric oxide synthase correlates with the angiogenic phenotype of and predicts poor prognosis in human gastric cancer. Gastric Cancer 2005; 8: 18-28.

[9] Alderton WK, Cooper CE, Knowles RG. Nitric oxide synthases: structure, function and inhibition. Biochem J 2001; 357: 593-615.

[10] Mozet C, Marin DG, Bertolini J, Tannapfel A, Wichmann G, Dietz A. Nitric oxide synthase (NOS2/3) expression in head and neck squamous cell carcinomas in correlation with clinical patterns. Onkologie 2009; 32: 655-660.

[11] Zhu Y, Jiang H, Chen Z, Lu B, Li J, Peng Y, et al. The genetic association between iNOS and eNOS polymorphisms and gastric cancer risk: a meta-analysis. Onco Targets Ther 2018; 11: 2497-2507.

[12] Yu X, Ge L, Niu L, Lian X, Ma H, Pang L. The Dual Role of Inducible Nitric Oxide Synthase in Myocardial Ischemia/Reperfusion Injury: Friend or Foe? Oxid Med Cell Longev 2018; 2018: 8364848.

[13] Nishank SS. Endothelial Nitric Oxide Synthase (eNOS) Gene Polymorphism is Associated with Age Onset of Menarche in Sickle Cell Disease Females of India. Mediterr J Hematol Infect Dis 2013; 5: e2013036.

[14] Huang CY, Hsieh MJ, Wu WJ, Chiang WL, Liu TC, Yang SF, et al. Association of endothelial nitric oxide synthase (eNOS) polymorphisms with EGFR-mutated lung adenocarcinoma in Taiwan. J Cancer 2018; 9: 2518-2524.

[15] Chen CH, Wu SH, Tseng YM, Hou MF, Tsai LY, Tsai SM. Distinct role of endothelial nitric oxide synthase gene polymorphisms from menopausal status in the patients with sporadic breast cancer in Taiwan. Nitric Oxide 2018; 72: 1-6.

[16] Di Salvatore M, Pietrantonio F, Orlandi A, Del Re M, Berenato R, Rossi E, et al. IL-8 and eNOS polymorphisms predict bevacizumab-based first line treatment outcomes in RAS mutant metastatic colorectal cancer patients. Oncotarget 2017; 8: 16887-16898.

[17] Tsay MD, Hsieh MJ, Wang SS, Wang WC, Chou YY, Shih CH, et al. Impact of endothelial nitric oxide synthase polymorphisms on urothelial cell carcinoma development. Urol Oncol 2019;

[18] Gao X, Wang J, Wang W, Wang M, Zhang J. eNOS Genetic Polymorphisms and Cancer Risk: A Meta-Analysis and a Case-Control Study of Breast Cancer. Medicine (Baltimore) 2015; 94: e972.

[19] Jang MJ, Jeon YJ, Kim JW, Chong SY, Hong SP, Oh D, et al. Association of eNOS polymorphisms $(-786 \mathrm{~T}>\mathrm{C}, 4 \mathrm{a} 4 \mathrm{~b}, 894 \mathrm{G}>\mathrm{T})$ with colorectal cancer susceptibility in the Korean population. Gene 2013; 512: 275-281.

[20] Su CW, Chien MH, Lin CW, Chen MK, Chow JM, Chuang CY, et al. Associations of genetic variations of the endothelial nitric oxide synthase gene and environmental carcinogens with oral cancer susceptibility and development. Nitric Oxide 2018; 79: 1-7.

[21] Lee CY, Ng SC, Hsiao YH, Yang SF, Hsu CF, Wang PH. Impact of the Receptor for Advanced Glycation End Products Genetic Polymorphisms on the Progression in Uterine Cervical Cancer. J Cancer 2018; 9: 3886-3893.

[22] Bharti AC, Shukla S, Mahata S, Hedau S, Das BC. Anti-human papillomavirus therapeutics: facts \& future. Indian J Med Res 2009; 130: 296-310.

[23] Baak JP, Kruse AJ, Robboy SJ, Janssen EA, van Diermen B, Skaland I. Dynamic behavioural interpretation of cervical intraepithelial neoplasia with molecular biomarkers. J Clin Pathol 2006; 59: 1017-1028. 
[24] Mehta AM, Mooij M, Brankovic I, Ouburg S, Morre SA, Jordanova ES. Cervical Carcinogenesis and Immune Response Gene Polymorphisms: A Review. J Immunol Res 2017; 2017: 8913860.

[25] Hefler LA, Ludwig E, Lampe D, Zeillinger R, Leodolter S, Gitsch G, et al. Polymorphisms of the endothelial nitric oxide synthase gene in ovarian cancer. Gynecol Oncol 2002; 86: 134-137.

[26] Wu X, Wang ZF, Xu Y, Ren R, Heng BL, Su ZX. Association between three eNOS polymorphisms and cancer risk: a meta-analysis. Asian Pac J Cancer Prev 2014; 15: 5317-5324.

[27] Haque S, Mandal RK, Akhter N, Panda AK, Hussain A, Khan S, et al. G894T and $4 \mathrm{a} / \mathrm{b}$ polymorphisms of NOS3 gene are not associated with cancer risk: a meta-analysis. Asian Pac J Cancer Prev 2015; 16: 2929-2937.

[28] Zhang L, Chen LM, Wang MN, Chen XJ, Li N, Huang YD, et al. The G894t, $\mathrm{T}-786 \mathrm{c}$ and $4 \mathrm{~b} / \mathrm{a}$ polymorphisms in Enos gene and cancer risk: a meta-analysis. J Evid Based Med 2014; 7: 263-269

[29] Ghilardi G, Biondi ML, Cecchini F, DeMonti M, Guagnellini E, Scorza R. Vascular invasion in human breast cancer is correlated to T-->786C polymorphism of NOS3 gene. Nitric Oxide 2003; 9: 118-122.

[30] Lee KM, Choi JY, Lee JE, Noh DY, Ahn SH, Han W, et al. Genetic polymorphisms of NOS3 are associated with the risk of invasive breast cancer with lymph node involvement. Breast Cancer Res Treat 2007; 106: 433-438.

[31] Casadei Gardini A, Marisi G, Faloppi L, Scarpi E, Foschi FG, Iavarone M, et al. eNOS polymorphisms and clinical outcome in advanced HCC patients receiving sorafenib: final results of the ePHAS study. Oncotarget 2016; 7: 27988-27999.

[32] Di Salvatore M, Lo Giudice L, Rossi E, Santonocito C, Nazzicone G, Rodriquenz MG, et al. Association of IL-8 and eNOS polymorphisms with clinical outcomes in bevacizumab-treated breast cancer patients: an exploratory analysis. Clin Transl Oncol 2016; 18: 40-46.

[33] Chen CA, Liu CY, Chou HH, Chou CY, Ho CM, Twu NF, et al. The distribution and differential risks of human papillomavirus genotypes in cervical preinvasive lesions: A Taiwan Cooperative Oncologic Group Study. Int J Gynecol Cancer 2006; 16: 1801-1808. 